\title{
BRECHA DIGITAL Y DERECHOS FUNDAMENTALES: LAS NUEVAS TECNOLOGÍAS EN EL PROCESO PENAL PERUANO
}

\author{
DIGITAL DIVIDE AND FUNDAMENTAL RIGHTS: THE NEW TECHNOLOGIES IN \\ THE PERUVIAN CRIMINAL PROCESS
}

\section{Dennis José Almanza Torres}

Profesor asociado en la Universidad la Salle (Perú). Profesor contratado en la Universidad Nacional de San Agustín y Universidad Católica de Santa María (Perú). Doctor y Maestro en Derecho por la Universidade Federal do Paraná UFPR (Brasil).

\section{Flor Zúñiga Maldonado}

Maestra en Derecho por la Universidade Federal do Paraná UFPR (Brasil). Graduada en Derecho por la Universidad Nacional de San Agustín (Peru). Abogada principal en A\&Z abogados asociados.

\section{Resumen}

La informatización del proceso judicial es una realidad en diferentes países. En el Perú, este proceso viene implementándose paulatinamente; no obstante, encuentra un serio obstáculo en la sociedad peruana donde la brecha digital entre excluidos e incluidos digitalmente es alta. El problema se agrava cuando las nuevas tecnologías son utilizadas como herramientas en el proceso penal donde derechos fundamentales son discutidos. En el presente trabajo se analiza el proceso de informatización del sistema de justicia peruano, demostrando graves falencias al no considerar este proceso, la brecha digital existente.

Palabras clave: Derechos fundamentales, proceso penal, expediente electrónico, brecha digital.

\section{Abstract}

The computerization of the judicial process is a reality in different countries. In Peru, this process has been gradually implemented; 
however, it encounters a serious obstacle in Peruvian society, where the digital gap between the excluded and the digitally included is high. The problem is exacerbated when new technologies are used as tools in the criminal process where fundamental rights are discussed. In this paper, the computerization process of the Peruvian justice system is analyzed, showing serious flaws, because this process did not consider the existing digital gap.

Keywords: Fundamental rights, criminal process, electronic court record, digital divide.

\section{INTRODUCCIÓN}

La presencia de las tecnologías de la información y de la comunicación en nuestros quehaceres diarios, generó grandes cambios en nuestra sociedad. La expansión de estas tecnologías se acentuó a fines del siglo pasado a través de la llamada revolución informática; no obstante, es en el presente siglo cuando las nuevas tecnologías de la información y de la comunicación (NTIC) se consolidan como herramientas facilitadoras de la convivencia social.

Las NTIC no son exclusivas del mundo privado, la administración pública también recurre a estas herramientas con el fin de tornar eficientes sus actividades, en ese sentido, el Poder Judicial peruano, teniendo como soporte los avances en las Nuevas Tecnologías y su réplica en varios campos, preparó una serie de medidas con la finalidad de implementar el expediente electrónico. Este proyecto viene concretándose paulatinamente, siendo visibles algunos resultados que permiten comprobar los beneficios de este proceso; sin embargo, también saltan a la luz, barreras y dificultades que afrontan, principalmente, las partes que se ven obligadas a actuar en este nuevo entorno.

La modernización del Poder Judicial por medio de técnicas electrónicas e informáticas, pretende que los diversos actores del proceso, como los tribunales, los profesionales del derecho y el público en general, se valgan de diferentes medios informáticos - como el internet - para vehicular la información necesaria y facilitar la solución de las controversias con mayor rapidez y eficiencia.

Los beneficios de la puesta en marcha del expediente electrónico son notoriamente visibles, se reflejan en la agilidad y dinámica del proceso, es decir en el 
desarrollo efectivo de un proceso judicial en un tiempo razonable. Sin embargo, la implementación del expediente electrónico, no está circunscrito a la entrada en vigencia de una norma que obligue o incentive su aplicación, este proceso, por su naturaleza, implica mucho más.

La informatización del proceso se viene expandiendo a juzgados que tramitan causas en las diversas ramas del derecho; no obstante, las deficiencias en la implementación de un expediente electrónico, salen a flote y traen consecuencias graves cuando el expediente es tramitado en un proceso penal, donde derechos fundamentales, como la libertad del individuo, ${ }^{1}$ son discutidos.

El Nuevo Código Procesal Penal peruano, que adoptó un modelo acusatorio adversarial garantista, viene implementándose paulatinamente a partir del año 2006 para regular el proceso penal en sus diferentes etapas. Este proceso es regido por diversos principios, parte de los cuales están establecidos en la Constitución Política del Perú (CPP), como son²: la observancia del debido proceso y la tutela jurisdiccional; la publicidad en los procesos, salvo disposición contraria de ley; la motivación escrita de las resoluciones judiciales en todas las instancias, excepto los decretos de mero trámite, con mención expresa de la ley aplicable y de los fundamentos de hecho en que se sustentan; el principio de no ser penado sin proceso judicial; el principio de no ser privado del derecho de defensa en ningún estado del proceso; el principio de que toda persona debe ser informada, inmediatamente y por escrito de las causas o razones de su detención; y el principio del derecho de toda persona de formular análisis y críticas de las resoluciones y sentencias judiciales, con las limitaciones de ley. Asimismo, el Código procesal penal también hace referencia a principios que deben guiar la actuación de los sujetos que participan en un proceso penal, estos son: el principio acusatorio, de igualdad de armas, de contradicción, de inviolabilidad del derecho de defensa, de presunción de inocencia, de publicidad de juicio, de oralidad, de inmediación, de identidad personal y de unidad y contradicción (CUBAS VILLANUEVA, 2005, p. 157162).

Si bien la utilización de la NTIC, pretende asignar celeridad y eficiencia al proceso penal, esta debe darse en armonía con los principios constitucionales

\footnotetext{
${ }^{1}$ Al respecto el Capítulo I de la Constitución Política del Perú, referido a los Derechos Fundamentales de la Persona, establece en su artículo $2^{\circ}$, Toda persona tiene derecho a (24) A la libertad y a la seguridad personales.

2 Constitución Política del Perú. Artículo 139. Principios de la función jurisdiccional.
} 
señalados, y con los principios inherentes al proceso penal, tal y como corresponde a un estado constitucional de derecho. En consecuencia los sujetos que actúan en este proceso ${ }^{3}$ - el Ministerio público, la policía nacional, el imputado, el abogado defensor, el agraviado, el actor civil, el querellante particular y el tercero civil - deben conocer las herramientas propias a las NTIC para, de esta manera, poder ejercer sus derechos y actuar debidamente en el proceso.

La informatización del proceso penal, aparentemente, no tomó en consideración esta necesidad, pues la implementación del expediente electrónico, colisiona con diversas barreras que fueron ignoradas en su momento como: los sistemas operativos desactualizados y deficientes, la informatización incompleta de los sistemas de justicia, y principalmente la amplia brecha digital y la brecha procesal electrónica existente en nuestro país.

Considerando las políticas que promueven la informatización del proceso judicial y el nivel de acceso a las NTIC por la población peruana, en el presente trabajo se analiza y cuestiona la informatización del proceso penal peruano al vulnerar derechos fundamentales recogidos en la Constitución peruana, debido a la amplia brecha que existe entre ciudadanos incluidos y excluidos digitalmente.

\section{ESTADO CONSTITUCIONAL Y DERECHOS FUNDAMENTALES}

Concluida la segunda guerra mundial, en varios países de Europa occidental y del mundo entero, se dieron importantes cambios en el campo jurídico, dentro de estos, dos fueron los más importantes: el primero, netamente estructural, la constitucionalización del derecho, y desde una perspectiva doctrinal, la afirmación del neoconstitucionalismo. ${ }^{4}$ Ambos, son recíprocos, ya que el uno favorece y sustenta al otro. (COMANDUCCI, 2009, p. 85).

El primero de ellos, que refleja lo sucedido en los países de Europa continental a partir de la segunda mitad del siglo XX, está referido al proceso mediante el cual el derecho es "impregnado", "saturado" o "embebido" por la

\footnotetext{
3 Las funciones, derechos, deberes y obligaciones de los sujetos procesales se encuentran establecidos en la sección IV, del libro I, (Artículo 60 al 113) del Código Procesal Penal Peruano.

${ }^{4}$ Atria (2004), resaltando la importancia de este fenómeno señala: "Un nuevo fantasma recorre Europa - el fantasma del neo-constitucionalismo. Los poderes de la cultura jurídica europea han entrado en una santa alianza no para exorcizarlo sino para defenderlo e incluso exportarlo: jueces y abogados, académicos y profesores de derecho, intelectuales italianos y filósofos alemanes". ( $p$. 118).
} 
Constitución: "un derecho constitucionalizado se caracteriza por una Constitución invasiva, que condiciona la legislación, la jurisprudencia, la doctrina y los comportamientos de los actores políticos". (COMANDUCCI, 2009, p. 119) Este renacimiento del Derecho Constitucional conllevó a la reconciliación entre el derecho y la moral, postura que había sido cuestionada por el positivismo jurídico. (AGUILERA PORTALES y LÓPEZ SÁNCHEZ, 2009, p. 413)

El principio de supremacía de la constitución que tiene como característica principal la relación de superioridad y subordinación en la que se encuentran el resto de normas, hace que "en el estado Constitucional, para ser válida, una norma tiene que no contradecir la Constitución, que no ir en contra de los principios y de los derechos fundamentales allí recogidos", (ATIENZA, 2009, p. 20,21) ${ }^{6}$ puesto que:

suas normas são qualitativamente distintas e superiores às outras normas do ordenamento jurídico, uma vez que incorporam o sistema de valores essenciais à convivência social, devendo servir como parâmetro de confronto para todo o ordenamento jurídico, além de auxiliar a este como critério informativo e interpretativo validante. (FACCHINI, 2010, p. 58).

Por su parte, el neoconstitucionalismo como corriente de pensamiento, tiene como objetivo primordial "concretizar los valores y principios constitucionales por medio de la interpretación y argumentación". (AGUILERA PORTALES y LÓPEZ SÁNCHEZ, 2009, p. 412).

Es así como al finalizar la segunda guerra mundial el "Direito constitucional já havia iniciado uma redefinição de seus traços característicos com vistas a se identificar com uma constelação de valores considerados fundamentais, entre eles, o respeito e a realização da pessoa humana na sua especial dignidade de ser e amar". (ROSSI, 2011, p. 142,143) De la misma forma, este nuevo constitucionalismo, propone, entre sus objetivos, garantizar y expandir derechos individuales, entre ellos: "derechos al debido proceso (...), a la igualdad, a la libertad de asociación, de movimiento, de expresión y de creencia; y a la educación, el trabajo, la salud y la seguridad económica”.(MERRYMAN, 2009, p. 291).

\footnotetext{
${ }^{5}$ En el mismo sentido ver: ATRIA, (2004, p. 119).

${ }^{6} \mathrm{Al}$ respecto Zagrebelsky (2011) afirma: "La ley, por primera vez en la época moderna, viene sometida a una relación de adecuación, y por tanto de subordinación, a un estrato más alto de derecho establecido por la Constitución". (p. 34). En sentido similar Fachin (2015) señala: "No Brasil, ao longo da historia mais recente, o Código Civil perdeu para a Constituição a posição de centralidade da ordem jurídica privada". (p. 63).
} 
En América Latina, el giro doctrinal hacia una principiología jurídicoconstitucional puede ser asociado a lo sucedido en esta parte del continente durante las últimas décadas del siglo $\mathrm{XX}$, donde, luego de periodos de regímenes autoritarios con consecuencias desastrosas sobre las libertades políticas y civiles, (NEVES, 2013. P. 171) ocurrieron procesos de democratización y constitucionalización.

En el Perú, como en el resto de países que optaron por adherirse a este proceso, se cuenta con una Constitución colmada de derechos, la cual condiciona a la jurisprudencia, al legislativo y a otros actores políticos.

El capítulo I del Título I de la Constitución Política del Perú, bajo el título de derechos fundamentales de la persona, recoge una lista de derechos inherentes a la concretización del fin supremo de la sociedad y del Estado, esto es, de la dignidad de la persona.

Estos derechos fundamentales, por su naturaleza y ubicación en el ordenamiento jurídico, son parámetros inquebrantables que limitan la extensión del propio ordenamiento, es decir, las normas inferiores deben estructurarse sin ignorar estas, menos aún contrariarlas. Su trascendencia es aplicable al ordenamiento jurídico en su integridad, incluyendo, claro está, las normas que regulan el proceso penal.

\section{LOS PRINCIPIOS DEL NUEVO PROCESO PENAL PERUANO}

El artículo 43 de la Constitución Política del Perú, establece que el Perú es un Estado de Derecho, esto representa la prevalencia de una Ley Suprema que consagra determinados derechos fundamentales inherentes a la personalidad humana. $^{7}$

El Nuevo Código Procesal Penal peruano, basado en un modelo acusatorio adversarial garantista, publicado el 29 de julio del año 2004 mediante Decreto Legislativo № 957 y que viene implementándose paulatinamente a partir del año $2006,{ }^{8}$ se inspira en el mandato constitucional de respeto y garantía a los derechos fundamentales de la persona y busca establecer un equilibrio entre estos derechos y

\footnotetext{
${ }^{7}$ Academia de la Magistratura. Código Procesal Penal - Manuales Operativos. (2007, p. 26).

${ }^{8}$ Actualmente este texto está vigente en la mayoría de departamentos del Perú, restando entrar en vigencia solamente en la capital del Perú (Lima), habiéndose programado su implantación el año 2018.
} 
las facultades de persecución y sanción penal del estado a través de sus órganos competentes. $^{9}$

Este Código, que regula el proceso penal en sus diferentes etapas como son: Investigación preparatoria, etapa intermedia o de control y etapa de juzgamiento; busca mejorar de manera efectiva el sistema nacional de justicia, para ello, su estructura y organización están orientados a concretar aspectos fundamentales en el proceso, entre ellos: acercar al ciudadano al ideal de justicia pronta y cumplida, "potenciar el derecho a la defensa y asegurar, en lo posible, la vigencia de los derechos humanos cuando el Estado hace valer su pretensión punitiva". (DELGADO MENÉNDEZ, 2010, p. 69)

El título preliminar del referido documento, destaca la importancia de los principios y garantías que regulan el nuevo proceso, así como la preponderancia que ostentan los derechos fundamentales. Así, una de los principios baluartes del proceso penal señalados en el texto es la defensa del principio de igualdad. La igualdad con la que deben actuar las partes en un proceso penal, está expresada en el inciso 03 del artículo 01 del Título Preliminar del Código Procesal Penal, el mismo que señala que: "Las partes intervendrán en el proceso con iguales posibilidades de ejercer las facultades y derechos previstos en la Constitución y en este Código. Los jueces preservaran el principio de igualdad procesal debiendo allanar todos los obstáculos que impidan o dificulten su vigencia”. El principio de igualdad de armas, como explica Cubas Villanueva (2005), busca reconocer a las partes los mismos medios de ataque y de defensa. Este principio es una extensión del principio de igualdad establecido en el inciso 02 del artículo 02 de la Constitución Política del Perú. ${ }^{10}$ Es evidente que para ejercer el derecho de igualdad es indispensable conocer el proceso y los medios con los que se cuenta para ejercer sus derechos y realizar las acciones correspondientes.

El principio a la igualdad está estrechamente relacionado con la posibilidad que tienen las partes para oponer argumentos y razones para respaldar sus posiciones, es decir, con el principio de contradicción. Este principio se encuentra reconocido en el inciso 02 del artículo 01 del Título Preliminar el cual señala que “Toda persona tiene derecho a un juicio previo, oral, público y contradictorio (...).”, el

\footnotetext{
${ }^{9}$ Academia de la Magistratura. Código Procesal Penal - Manuales Operativos. (2007, p. 28,29).

${ }^{10} \mathrm{Al}$ respecto el inciso 02 del referido artículo señala: Toda persona tiene derecho: 2) A la igualdad ante la ley. Nadie debe ser discriminado por motivo de origen, raza, sexo, idioma, religión, opinión, condición económica o de cualquier otra índole.
} 
mismo que debe ser leído en concordancia con lo señalado en el artículo $356^{\circ}$ del Código Procesal Penal.

Por otro lado, el artículo VI del Título preliminar destaca la relevancia de los derechos fundamentales, señalando bajo qué circunstancias, estos podrían ser limitados, así el referido artículo señala: "Las medidas que limitan derechos fundamentales, salvo las excepciones previstas en la Constitución, solo podrán dictarse por la autoridad judicial, en el modo, forma y con las garantías previstas en la Constitución. (...)". Es decir, como explican Gálvez Villegas, Rabanal Palacios y Castro Trigoso (2008, p. 61) en el curso de la investigación, ciertos derechos fundamentales como la integridad física, la libertad individual, la intimidad, la inviolabilidad del domicilio, el secreto de las comunicaciones, entre otros, pueden verse limitados, ello debe darse en conformidad con lo establecido en los artículos 202 y 203 del referido código ${ }^{11}$ y con las debidas garantías para el afectado, previstas tanto en el Código, como en la Constitución. Ello es resaltado por San Martin (2003, p. 563) quien afirma: "En tanto todo derecho fundamental tiene una eficacia vinculante, por ser un componente estructural básico del conjunto del ordenamiento jurídico y de cada una de sus ramas, es de tener en consideración que su afectación o limitación debe respetar: a) los límites impuestos en la propia

${ }^{11}$ En ese sentido, el referido texto establece:

TíTULO III la búsqueda de pruebas y restricción de derechos capítulo i. Preceptos generales.

Artículo $202^{\circ}$.- Legalidad procesal. Cuando resulte indispensable restringir un derecho fundamental para lograr los fines de esclarecimiento del proceso, debe procederse conforme a lo dispuesto por la Ley y ejecutarse con las debidas garantías para el afectado.

Artículo $203^{\circ}$.- Presupuestos

1. Las medidas que disponga la autoridad, en los supuestos indicados en el artículo anterior, deben realizarse con arreglo al principio de proporcionalidad y en la medida que existan suficientes elementos de convicción. La resolución que dicte el Juez de la Investigación Preparatoria debe ser motivada, al igual que el requerimiento del Ministerio Público.

2. Los requerimientos del Ministerio Público serán motivados y debidamente sustentados. El Juez de la Investigación Preliminar, salvo norma específica, decidirá inmediatamente, sin trámite alguno. Si no existiere riesgo fundado de pérdida de finalidad de la medida, el Juez de la Investigación Preliminar deberá correr traslado previamente a los sujetos procesales y, en especial, al afectado. Asimismo, para resolver, podrá disponer mediante resolución inimpugnable la realización de una audiencia con intervención del Ministerio Público y de los demás sujetos procesales, que se realizará con los asistentes.

3. Cuando la Policía o el Ministerio Público, siempre que no se requiera previamente resolución judicial, ante supuestos de urgencia o peligro por la demora y con estrictos fines de averiguación, restringa derechos fundamentales de las personas, corresponde al Fiscal solicitar inmediatamente la confirmación judicial. El Juez de la Investigación Preparatoria, sin trámite alguno, decidirá en el mismo día o a más tardar al día siguiente confirmando o desaprobando la medida ejecutada por la Policía o la Fiscalía, salvo que considere indispensable el previo traslado a los sujetos procesales o, en su caso, la realización de una audiencia con intervención del Fiscal y del afectado. La resolución que ordena el previo traslado o la audiencia no es impugnable.

4. Respecto de la realización de la audiencia, rige en lo pertinente el artículo $8^{\circ}$ 
Constitución. (...)."

Finalmente, y englobando a los principios abordados, es necesario destacar la importancia del principio de inviolabilidad del derecho de defensa el cual se encuentra consagrado en el inciso 14 del artículo 139 de la Constitución Política del Perú en los siguientes términos: "Son principios y derechos de la función jurisdiccional: 14) El principio de no ser privado del derecho de defensa en ningún estado del proceso (...)." Este derecho, referido a la capacidad que tiene un sujeto de defenderse en un proceso, está supeditado al hecho de conocer el proceso. En ese sentido, es obligación del órgano jurisdiccional poner en conocimiento de las partes todo lo referente al proceso penal que se viene tramitando; de esta manera, las partes, luego de conocer el proceso, pueden ejercer su derecho de defensa. Al respecto, el artículo IX del Título Preliminar del Código Procesal Penal peruano señala:

Toda persona tiene derecho inviolable e irrestricto a que se le informe de sus derechos, a que se le comunique de inmediato y detalladamente la imputación formula en su contra y a ser asistida por un Abogado Defensor de su elección o, en su caso por un ahogado de oficio, desde que es citada o detenida por la autoridad.

Garantizar que las partes conozcan el proceso así como sus derechos, es fundamental, puesto que de esta forma "posibilita el ejercicio de los demás derechos reconocidos por la Constitución, los Tratados Internacionales de Derechos Humanos y las normas procesales" (CUBAS VILLANUEVA, 2005, p. 159-160).

De esta manera se observa la importancia de los principios en el proceso penal, en especial en el sistema procesal penal acusatorio, pues este debe mantener una estrecha relación y concordancia con los pilares de un sistema republicano y los sólidos principios de un Estado Constitucional de Derecho.

Finalmente, debemos indicar que la reforma procesal penal peruana, que busca la consagración de los principios señalados, como explica San Martin (1988, p. 227), encuentra su sustento en dos grandes anomalías del sistema penal peruano, por un lado la falta de celeridad en los procesos, lo que se refleja en una alta tasa de presos sin condenas y de causas prescritas, y por el otro, la necesidad de un proceso eficaz, esto es, un proceso donde la impunidad no campee y en consecuencia la falta de seguridad ciudadana no sea una constante.

En razón de que la demora en el trámite de un proceso penal es una 
constante, la cual per se, vulnera derechos y principios de las partes, el estado peruano decidió valerse de las nuevas tecnologías para mitigar o, en lo posible, eliminar las deficiencias y demoras en este proceso.

\section{EL GOBIERNO ELECTRÓNICO Y SUS APLICACIONES EN EL ESTADO PERUANO}

La tecnología de la información está referida al conjunto de recursos tecnológicos empleados para el uso de la información o aun, de recursos no humanos dedicados al almacenamiento, procesamiento y comunicación de la información (WACHOWICZ, y CASAGRANDE, 2012, p. 95)

$\mathrm{Si}$ bien fue en la década de los 90 que se expandieron las nuevas tecnologías, los orígenes de la revolución tecnológica son hallados en abril de 1969 con el surgimiento del Arpa-Net con fines estrictamente militares. Posteriormente, en las décadas de los 80 e inicios de los 90 , el internet pasó a ser utilizado solo para fines académicos. Solamente en 1990 con la ayuda del Inglés Tim Bernes-Lee se desarrolla el servicio World Wide Web (www), o simplemente web; con este nuevo servicio, el internet logra ampliar sus horizontes e iniciar su proceso de expansión por el mundo entero. (FREITAS, 2012, p. 51).

En un inicio estas tecnologías estaban referidas a la información bajo un enfoque clásico (entendido como transmisión de datos sobre algo o alguien, por lo general noticias que llegaban al receptor con cierto intervalo de tiempo), actualmente, la idea ha sido alterada pues en este siglo el término información está relacionado al contenido y a la integración de diferentes fuentes de conocimiento. (FREITAS, 2012, p. 50)

Las Nuevas Tecnologías de la Información pretenden o fueron creadas para acelerar el desarrollo de la sociedad con base en el conocimiento, dando origen así, a la llamada sociedad del conocimiento donde, según Miège (Citado por DRUETA, 2008, p. 67), "la información y el conocimiento ocupan un lugar sustantivo y se convierten en fuente de riqueza al ser incorporados a los procesos productivos y educativos".

En varios países, los órganos de gobierno decidieron valerse de estos conocimientos a través de reformas administrativas y la creación de un nuevo concepto, el Gobierno Electrónico (e-gob.). 
En el Perú, como en otros países de la región, la modernización del Estado durante los últimos años se basó en una gestión práctica con miras al cumplimiento de metas y a la obtención de mayor eficiencia; es por ello que la reforma del Estado obligó a revisar roles, funciones y mecanismos de funcionamiento dentro del aparato estatal para luego adecuarlos a las exigencias de la Nueva Gestión Pública. (MEZZAROBA, BERNIERI, y BIER, 2014, p. 23,24)

La New Public Management, cuyo origen se remonta a las reformas administrativas realizadas en Gran Bretaña en la década de los 80 , se refiere a las mudanzas organizativas, directivas y operacionales que se dieron en el sector púbico de varios países durante esa década y años posteriores. Esta Nueva Gestión tiene como una de sus principales características "el énfasis en la observancia de las "E" (economía, eficiencia y eficacia) en las operaciones administrativas, que conduce a reformas profundas del sistema presupuestal y del control interno de gestión, con el apoyo de la incorporación de las nuevas tecnologías de información”."(AGUILAR VILLANUEVA, 2006, p. 144-150)

En el seno de la Nueva Gestión Pública surgió el e-gob, el cual es definido por la Organización de las Naciones Unidas (ONU) como el uso de las Tecnologías de la Información y de la Comunicación (TIC) por parte del Estado, para brindar servicios e información a los ciudadanos, aumentar la eficacia y eficiencia de la gestión pública, e incrementar sustantivamente la transparencia del sector público y la participación ciudadana.

Este sistema atraviesa un proceso evolutivo según la adopción de sus herramientas por parte de un gobierno, la ONU ha distinguido cinco niveles evolutivos de acuerdo al grado de desarrollo en el que se encuentran, estos son: (i) Presencia emergente, cuando las herramientas del gobierno electrónico se utilizan solamente para brindar información a través de Internet, (ii) Presencia ampliada, cuando la presencia se expande por medios sofisticados, incluyendo búsquedas en web sites y comunicación por medio de correos electrónicos, (iii) Presencia interactiva, las organizaciones gubernamentales están presentes masivamente en las páginas web otorgando algunos servicios como el llenado de formularios electrónicos, (iv) Presencia transaccional, cuando el Estado ofrece transacciones completas y seguras propias de la Administración, como el otorgamiento de pasaportes o de certificados. (v) Integración total, cuando existe una relación integrada entre el usuario y el Estado, pues este no percibe la diferencia entre los 
servicios on line y los físicos.(NASSER y CONCHA, 2011, p. 15,16) ${ }^{12}$

Si bien el gobierno electrónico, ofrece innumerables ventajas para el usuario, debe tenerse en cuenta que para el correcto funcionamiento de este sistema es necesario satisfacer ciertos requerimientos; entre ellos, los de interoperabilidad, infraestructura, legales y de seguridad sobre servicios transaccionales.

\section{LAS NUEVAS TECNOLOGÍAS DE LA INFORMACIÓN Y COMUNICACIÓN Y LA ADMINISTRACIÓN DE JUSTICIA.}

El proceso judicial, como método de solución de conflictos es dinámico y como consecuencia de ello, el tiempo de duración de un proceso es uno de sus elementos característicos y naturales; por lo tanto cuando se piensa en efectividad, se tiene en mente un proceso que conceda tutela a quien demuestra tener razón en el menor tiempo posible; revelando la estrecha relación que existe entre efectividad de la tutela jurisdiccional y la duración temporal del proceso.

La informatización del proceso judicial es un fenómeno que ya viene siendo tratado hace más de dos décadas. Las primeras utilizaciones fueron limitadas a la prestación de servicios de información a través de computadores de los órganos del Poder Judicial, y a proveer información al público por medio de sus páginas web con la intención de aumentar la transparencia y legitimidad de sus tribunales, además de otorgar una aproximación inicial a los potenciales usuarios.

Este panorama ha cambiado, actualmente la utilización de las Nuevas Tecnologías están siendo orientadas al mejoramiento del acceso a la justicia, sea por medio del intercambio de datos electrónicos entre entes judiciales o mediante la oferta de servicios judiciales por internet. (CONTONI y VELICOGNA, s/a, p. 30)

Es en ese contexto que surge el proceso judicial electrónico, el cual es entendido como "el proceso judicial en el que se tramitan y resuelven las controversias con el soporte de las tecnologías de la información y las comunicaciones (TIC)" (SALAS FERRO, 2019, p. 17). Este proceso en el Perú, opera por medio del expediente judicial electrónico, entendido este como el conjunto

\footnotetext{
12 NASER, Alejandra y CONCHA, Gastón. El gobierno electrónico en la gestión pública, p. 15-16. Disponible http://repositorio.cepal.org/bitstream/handle/11362/7330/S1100145 es.pdf?sequence=1. Acceso en: $18 / 05 / 2015$.
} 
de documentos electrónicos que pertenecen a un proceso judicial desarrollado a través de medios informáticos; ${ }^{13}$ es decir la utilización del expediente electrónico exige que todas las actuaciones procesales plasmadas en documentos, se encuentren digitalizadas y hospedadas en la plataforma virtual en la que se desarrolla el proceso, llegando a formar un macro documento electrónico que contiene todas las actuaciones procesales y la documentación presentada o generada en el curso del proceso judicial.

El Texto Ùnico Ordenado de la Ley Orgánica del Poder judicial, que es el documento donde se establece la estructura del Poder Judicial peruano, así como los deberes y derechos de los Magistrados y servidores judiciales; en el inciso 31 del artículo 83, explica que dentro de las funciones y atribuciones del Consejo Ejecutívo del Poder Judicial esta el "Adoptar acuerdos y demás medidas necesarias para que las dependencias del Poder Judicial funcionen con celeridad y eficiencia", con base en esta potestad, el Consejo Ejecutivo del Poder Judicial promulgó la Resolución Administativa № 228-2017-CE-PJ, de fecha 26 de Julio de 2017, mediante la cual se dispone la implementación del Expediente Judicial Electrónico (EJE) a nivel nacional y en todas las especialidades. Asimismo, esta Resolución, en su artículo tercero, aprueba el Reglamento del Expediente Judicial Electrónico, indicando que el mismo es de obligatorio cumplimiento para todos los órganos jurisdiccionales del poder judicial y para todo sujeto que participe en un proceso judicial.

El expediente judicial electrónico, montado sobre la plataforma Sistema Integrado Judicial Electrónico-Expediente Judicial Electrónico (SIJ-EJE), es un anhelo del sistema de justicia peruano; sin embargo, su implementación representa un gran esfuerzo por parte del estado; tanto los costos por la modernización del actual sistema de justicia, cuanto la capacitación de los operadores de justicia son los principales retos a vencer.

Dentro de los diversos beneficios que el proceso electrónico ofrece se tiene:

(i) Reducción en el tiempo de espera. El proceso judicial es una de las principales garantías constitucionales de la tutela jurisdiccional efectiva, por lo que la concurrencia al Poder Judicial en busca de hacer efectivo este derecho, no sólo debe comprender el cumplimiento de las garantías procesales de un debido proceso; sino también el desarrollo efectivo de un proceso judicial en un tiempo razonable; si

\footnotetext{
${ }^{13}$ El artículo 04 del Reglamento del Expediente Judicial Electrónico de Perú, lo define como: “Es la gestión del proceso judicial, sus actuaciones y los servicios que brinda a través de medios electrónicos seguros"
} 
no se cumpliese este requisito, el proceso resultaría inútil e injusto. Es evidente, entonces, que la efectividad del proceso está íntimamente ligada con su tiempo de duración; así lo han considerado incluso diversas Constituciones, como la Constitución Federal Brasilera de $1988^{14}$ y la Constitución Española de 1978, ${ }^{15}$ donde la duración razonable del proceso, constituye un derecho fundamental autónomo completo y válidamente reconocido. Asimismo Tratados Internacionales otorgan la debida importancia a este importante derecho. ${ }^{16}$

(ii) Incremento en productividad. Referida a la cantidad de proveídos emitidos por la Administración de Justicia, en el menor tiempo posible, ello permitiría un sistema de justicia eficiente y rápido.

(iii) Ahorro en papel. La reducción de costos en un proceso judicial se puede dar de diferentes maneras, una de ellas es la reducción de insumos, en este caso, la reducción del papel que se utiliza para plasmar los respectivos proveídos.

(iv) Gestión automatizada. La automatización de la gestión es una de las ventajas del expediente electrónico. La inmediatez con la que la Administración de justicia debe dar respuesta al ciudadano es una muestra de ello, pues ya no resultaría necesario, trámites demorados muchas veces sin utilidad alguna, los mismos que ocasionaban demora en el proceso judicial.

$\mathrm{Si}$ bien estos puntos representan un importante paso para concretar una Administración de justicia célere y veloz, para que estos puntos se concreten son necesarios determinados requisitos:

(i) Una alta inversión financiera por parte del Estado, la cual será justificada al permitir al ciudadano gozar de mayor confianza en el sistema judicial, pues considerará que la anhelada "Seguridad Jurídica" es una realidad.

(ii) Un tiempo prudencial para la capacitación de los operadores encargados de utilizar este nuevo sistema y que la implementación de la misma sea gradual, de tal forma que la implantación del sistema electrónico no se dé en un ambiente de desconfianza y desconocimiento.

(iii) Servidores informáticos modernos y actualizados con la capacidad suficiente para grabar y mantener disponible las actuaciones judiciales en las diferentes causas.

\footnotetext{
${ }^{14}$ Inciso LXXVIII, del artículo 5을 de la Constitución brasilera.

${ }^{15}$ En su artículo 24, la Constitución española hace referencia al derecho a un proceso público sin dilaciones indebidas.

${ }^{16}$ Como el Pacto de San José de Costa Rica.
} 
(iv) Operadores informáticos capacitados y honestos

(v) Las facultades de derecho deberán formar a sus estudiantes de grado y de posgrado con las habilidades necesarias para desenvolverse en este nuevo entorno, es decir, que tengan la capacidad suficiente para participar en un proceso judicial electrónico.

No obstante, estos requisitos no siempre se cumplen, esto conlleva a que la implementación del proceso electrónico sea tímida y esté propensa a presentar fallas, es por ello que la transformación del proceso simple en uno electrónico está siendo parcial y sectorizada, iniciándose en algunas regiones del país.

Uno de los cambios trascendentales se dio a mediados del año 2016 con la implementación del Sistema de Notificaciones Electrónicas (SINOE); $;{ }^{17}$ mediante este sistema se crea una casilla judicial electrónica donde los abogados reciben las comunicaciones enviadas por el Juzgado donde se tramita su causa; así, a través de este medio se pone en conocimiento de las partes de un proceso, las resoluciones, requerimientos, disposiciones y providencias correspondientes. ${ }^{18}$

El poder judicial peruano enfatizó la implementación del expediente judicial electrónico a partir de octubre del 2017 especialmente en materias Comercial, Laboral (NLPT), Tributario, Aduanero y de Mercado de la Corte Superior de Justicia de Lima. Este "segundo paso", consiste en la posibilidad de enviar, por parte de los abogados, escritos a los correspondientes órganos de justicia vía online, tal y como sucede con las notificaciones electrónicas, intercambiando el rol de los emisores y los receptores; asimismo, la posibilidad de visualizar el expediente judicial electrónico desde sus casas u oficinas las 24 horas del día, de lunes a domingo, a través de las casillas electrónicas, contribuyendo de esta manera con la transparencia en la administración de justicia. ${ }^{19}$

Resulta bastante alentadora esta iniciativa del Poder Judicial, no obstante son varias las dificultades que enfrenta el estado peruano al efectuar estos proyectos; por un lado, se tienen sistemas operativos deficientes y una informatización incompleta de los sistemas de justicia, los cuales están relacionados a problemas en

\footnotetext{
${ }^{17}$ Este proyecto denominado "Implementación del Sistema de Notificaciones Electrónicas (SINOE) en el ámbito nacional y en todas las especialidades", fue aprobado mediante Resolución Administrativa 069-2015-CE-PJ, del Consejo del Poder Judicial, de fecha, 12 de febrero del 2015.

18 Se puede acceder al sistema, previo registro a través del site: https://casillas.pj.gob.pe/sinoe/login.xhtml

19 En ese https://www.pi.gob.pe/wps/wcm/connect/eje/s eje/as prensa/as noticias/cs n nota+informativa vi sor expediente electronico. (Acceso en 01/02/2020).
} 
la forma como el presupuesto del Estado es distribuido. Por otro lado, este cambio exige que los actores de un proceso, como son: abogados, las partes, jueces, especialistas, auxiliares, fiscales, peritos, y todo sujeto que participé, deban de conocer el manejo de entornos virtuales; pues ellos, según corresponda, a través de la plataforma correspondiente deben presentar demandas y recursos, enviar documentos, realizar la lectura del íntegro del expediente, entre otros. (SALAS FERRO, 2019, p. 24,25); para ello están obligados a obtener sus certificados digitales, firmar electrónicamente, crear documentos digitales, digitalizar documentos físicos, usar la mesa de partes virtual y realizar una serie de actuaciones procesales en línea.

Estas habilidades necesarias para que las partes actúen en este entorno digital, son uno de los principales obstáculos para concretar la informatización del proceso judicial. Esto representa una limitación en el acceso a la justicia y, en consecuencia, una vulneración a determinados derechos. La ausencia de estas habilidades está relacionada con el insuficiente acceso a entornos y medios virtuales por parte de la población peruana, la que genera una amplia brecha digital en el país.

\section{LA BRECHA ELECTRÓNICA Y LOS DERECHOS FUNDAMENTALES}

La revolución que causaron las nuevas tecnologías durante la década de los 90, hizo que varios estudiosos - entre ellos Marc Prensky -, llamen a los nacidos de esta década para adelante, digital natives, o nacidos en la sociedad tecnológica. El resto de la población son considerados "migrantes"; aquellas personas que se esfuerzan por migrar para una sociedad nueva basada en aparatos tecnológicos y organizada socialmente por medio de la red mundial de computadoras (el internet). Estos serían los "digital immigrants", quienes a pesar de su esfuerzo, aún no consiguen igualarse a los natives, pues de una forma $u$ otra existen aspectos de las nuevas tecnologías que aún les resulta difícil de asimilar. (FREITAS, 2012, p. 51)

Debido al surgimiento y utilización de estas NTIC, y todo lo que ello acarrea, nuestra sociedad estaría dividida en dos polos opuestos: (i) los digitalmente incluidos, quienes son los detentores de las tecnologías dominantes, y (ii) los digitalmente excluidos, individuos que no tienen acceso a estos recursos. (MATTOS 
y SANTOS, 2009, p. 118) 20

En este contexto surge el concepto de inclusión digital, el cual según explica Kiomi Mori, (2011, p. 40,41) debe entenderse a partir de tres aristas: (i) de acceso, referida a la distribución de bienes y servicios que garanticen el acceso a la infraestructura de las nuevas tecnologías; (ii) de alfabetización digital, basada en las habilidades necesarias que permiten al individuo hacer uso de las TIC; y (iii) de apropiación de tecnologías, que implica que los individuos no sean solamente consumidores, sino que desarrollen una comprensión de las TIC que les permita apropiarse de ellas.

De esta manera, el desarrollo tecnológico intrínseco en la sociedad de la información puede generar efectos positivos o negativos para el hombre; puede incluirlo en esa nueva sociedad al posibilitarle el acceso a la información; o en contrapartida, puede excluirlo cuando este acceso a la información le es negado. (RIBEIRO, BENEDETTI y MACIEL, 2012, p. 70). En ese sentido Chacón Peganoro et.al (2017) explican: "Aquellos ciudadanos cuyo acceso a la innovación y a la tecnología hace parte de su espacio vital efectivo pero no tienen los medios suficientes para ello, padecen de lo que conocemos como brecha digital." (p.144).

Según el Informe Técnico Estadísticas de las Tecnologías de Información y Comunicación en los Hogares, divulgado por el Instituto Nacional de Estadística e Informática del Estado Peruano, correspondiente al trimestre julio/agosto/septiembre del 2019, ${ }^{21}$ solamente el $59,8 \%$ de la población de 6 y más años tienen acceso a Internet. Esta cifra es bastante alta pues de allí se desprende que actualmente en el Perú, de cada 100 habitantes mayores de 6 años, aproximadamente 40 no tendría acceso a Internet.

La distancia entre personas que utilizan el internet y quienes no utilizan se acentúa más cuando se separa a la población entre habitantes de áreas urbanas y habitantes de áreas rurales; así, en la zona urbana el 63.1\% tiene conexión, mientras que en la zona rural solamente el $22.5 \%$ de personas acceden a esta red. Respecto a esto último, la cifra es aún más preocupante, pues es de verse que en la zona rural del Perú, de cada 100 habitantes mayores de 6 años, 77 no tienen acceso

\footnotetext{
${ }^{20}$ El término "exclusión digital" o "digital divide" apareció por primera vez en 1995 en el periódico Los Angeles Times, en un artículo publicado por Jonathan Webber y Amy Harmon.

21 Información disponible en: https://www.inei.gob.pe/media/MenuRecursivo/boletines/ticdiciembre.pdf. Acceso en 12/02/2020.
} 
a internet. ${ }^{22}$

Con base en esta información, podemos señalar que en el Perú existe una gran parte de la población que no tiene acceso a entornos virtuales.

Si tenemos en cuenta que la administración de justicia busca hacer efectiva las leyes para todos sus habitantes, como corresponde a un estado de derecho, estaríamos frente a una gran dificultad, pues esta brecha digital impediría que ello se haga efectivo.

La imposibilidad de acceso a la información en un proceso judicial, debido al desconocimiento de medios tecnológicos e informáticos, conlleva a que los ciudadanos se dividan en dos grupos distanciados por una brecha judicial electrónica. Así, en un lado se tiene a quienes pueden acceder a las nuevas tecnologías para conocer un proceso judicial y de esta manera ejercer sus derechos y conocer sus deberes y obligaciones; y por el otro, quienes por su desconocimiento hacia las TICs, el proceso judicial electrónico les es ajeno, es decir, les es imposible conocer el desarrollo del proceso y todo lo que ello representa. Esto es muy grave cuando este distanciamiento se hace palpable en procesos que envuelven ramas del derecho donde derechos fundamentales son revisados.

En ese sentido, en un proceso judicial, la división entre los incluidos y excluidos digitalmente genera una barrera bastante sería, puesto que generalmente del acceso que las partes tengan a la información depende el resultado del proceso. Esta asimetría entre las partes (quienes tienen acceso y quienes no), afecta un importante derecho fundamental, este es el derecho a la igualdad. Al respecto conviene destacar lo afirmado por Gimeno Sendra (citado por CUBAS VILLEGAS, 2005 , p. 158) quien afirma que el derecho de igualdad se vulnera "cuando el legislador crea privilegios procesales carentes de fundamentación constitucional alguna o bien, el legislador, o bien el propio órgano jurisdiccional crean posibilidades procesales que se le niegan a la parte contraria". En este caso, la persona "excluida digitalmente", no estaría en igualdad de condiciones respecto a un "incluido digital", viéndose limitado para ejercitar integralmente su derecho a la defensa en un proceso judicial.

${ }^{22}$ Como dato adicional, según el referido informe, del total de la población que accede a Internet, el $63.1 \%$ son hombres y el $56.5 \%$ mujeres. Asimismo, el $90,2 \%$ utiliza Internet para comunicarse (correo o chat), el $89,3 \%$ de la población navega en Internet para obtener información, y el 85,5\% recurre a Internet para realizar actividades de entretenimiento como juegos de videos y obtener películas o música. 
Limitar el acceso de la información también afecta el derecho a la contradicción, pues la falta de conocimiento de las actuaciones procesales, impide a la parte cuestionar y contradecir las acusaciones que contra él pudieron realizarse, así como refutar las pruebas presentadas por el Ministerio Público, el actor civil o cualquier otro sujeto.

Finalmente, el principio de no ser privado del derecho de defensa en ningún estado del proceso puede verse seriamente afectado cuando las partes desconozcan o no tengan acceso a nuevas tecnologías; en consecuencia, para la utilización de estas TICs, como medios para transmitir información esencial en el proceso judicial, se debe tener en cuenta la posibilidad de acceso y conocimiento hacía estas tecnologías por parte del receptor, pues el ignorar ello atentaría contra este principio y desembocaría en una situación muy grave para la parte "excluida", ello considerando que lo que está en juego en estos procesos, muchas veces es la libertad del acusado.

La separación entre las partes de un proceso judicial que tienen acceso a las NTICs y las que no tienen, crea la brecha judicial electrónica; esta es una limitación para el goce de garantías procesales atentando contra derechos constitucionales y fundamentales. Corresponde al estado tomar las medidas necesarias para que está vulneración no se realice, puesto que como se indicó al inicio de este trabajo, la informatización del sistema de justicia implica mucho más que digitalizar documentos.

\section{CONCLUSIONES}

Las Nuevas Tecnologías de la Información pretenden o fueron creadas para acelerar el desarrollo de la sociedad con base en el conocimiento. Cuanto más generalizado es el acceso a la información, mayores serán las perspectivas de desarrollo; es por ello que en la sociedad de la información la verdadera riqueza del individuo se concentra y puede ser verificada por su nivel de conocimiento y de información acerca de la sociedad, del mercado y de la tecnología. Ese nivel de información tiende a influenciar directamente en la posición que este ocupará en la sociedad en la cual está inserido, determinando su inclusión como agente social, o su marginalización y consecuentemente su exclusión social. (MATOS, JAKOBI, y RIBEIRO, 2012, p. 122) 
El proceso electrónico busca que en el futuro se hable de un justicia en red, es decir un sistema integral e intercomunicado entre toda la Administración de Justicia, que entre otros objetivos garantice la interconexión telemática de la Administración de Justicia con las Administraciones Públicas, abogados, procuradores, y todos los relacionados a esta actividad, así como el acceso telemático de los ciudadanos a las sentencias y resoluciones judiciales en la medida en que sean públicas.

Con la implantación del Proceso Electrónico, se busca acabar, en la medida de lo posible, con la imagen de lentitud en la resolución de conflictos que soporta el Poder Judicial y de esa manera otorgar al justiciado tutela efectiva en plazos razonables; por lo tanto, el proceso electrónico es un medio por el cual sería posible traer a la realidad jurídica, la obtención de respuestas efectivas al derecho que se pleitea, siendo el inicio para la quiebra del rotulo que ostenta el Poder Judicial en cuanto a la demora en la prestación jurisdiccional, siendo así capaz de efectivizar el derecho fundamental a la duración razonable del proceso.

Frente a este panorama, alentador para los usuarios y la Administración Judicial, se observan ciertas barreras que el Estado aún no ha podido derrumbar, esto implica dificultades al utilizar las NTICs en la Administración de Justicia, pues la modernización de la Justicia y la propuesta para introducir las nuevas tecnologías tiene que tener en cuenta no solo el aspecto técnico, sino también el organizativo y el cultural.

Dentro de las barreras, destaca la segmentación que existe entre los incluidos y excluidos digitalmente, pues esta separación afectaría a determinados principios propios al proceso penal en una sociedad democrática, colocando en una posición de "desventaja" a quienes no tienen acceso a los medios informáticos. Esto es sumamente peligroso en las materias que discuten derechos fundamentales como la libertad de las personas. Es por ello que consideramos que la informatización de la justicia debe ser planeada abarcando estudios sociológicos, antropológicos y culturales pues una sociedad ampliamente desigual y pluricultural como la peruana necesita diagnósticos previos y posteriormente, políticas públicas que busquen incluir digitalmente a todos los ciudadanos.

Además de la brecha procesal, deficiencias técnicas y falta de modernización de sistemas informáticos son otras dificultades con las que tienen que pleitear diariamente quienes participan de la justicia electrónica. Corresponde al Estado por 
lo tanto, subsanar urgentemente estas deficiencias, pues carece de sentido la implantación de una e-justicia valiéndose de instrumentos con capacidad insuficiente para almacenar y manipular los programas informáticos necesarios, esto, además de generar costos, conlleva a una mayor inseguridad jurídica. 


\section{REFERENCIAS BIBLIOGRÁFICAS}

Academia de la Magistratura. Código Procesal Penal - Manuales Operativos. Lima: Editorial Super Gráfica, 2007.

AGUILERA PORTALES, Rafael y LÓPEZ SÁNCHEZ, Rogelio. Interpretación judicial y principios jurídicos fundamentales en el estado democrático y social de derecho. In: Interpretación y razonamiento jurídico. Lima: Ara, 2009, p. 404-437.

AGUILAR VILLANUEVA, Luis F. Gobernanza y gestión pública, México: Fondo de cultura económica, 2006.

ALMANZA TORRES, Dennis J. y ZÚÑIGA MALDONADO, Flor. Inclusión digital y desarrollo: críticas a las "clásicas" definiciones. In: Derecho y Cambio social, № 40, año 2015, p. 1-11. Disponible en:

http://www.derechoycambiosocial.com/revista040/INCLUSION DIGITAL Y DESAR ROLLO.pdf

ATIENZA. Constitucionalismo, globalización y derecho. In: Interpretación y razonamiento jurídico. Lima: ARA, 2009.

ATRIA, Fernando. La ironía del positivismo jurídico. In: Doxa: Cuadernos de Filosofía del Derecho $n^{\circ}$ 27. Alicante: Universidad de Alicante, 2004, p. 81-139.

COMANDUCCI, Paolo. "Constitucionalización y neoconstitiucionalismo", en Comanducci, Paolo., Ahumada, M. A., y Gonzáles Lagier, D., Positivismo jurídico y neoconstitucionalismo, Madrid, Fundación Coloquio Jurídico Europeo, 2009, p. 85121.

CONTONI, Francesco y VELICOGNA, Marco. Del acceso a la información al acceso a la justicia: Diez años de e-justice en Europa. In: Sistemas Judiciales. Una perspectiva integral sobre la administración de justicia. Santiago de Chile: Centro de Estudios de Justicia de las Américas CEJA, s/a, p. 30-47.

CUBAS VILLANUEVA, Víctor. Principios del Proceso Penal en el Nuevo Código Procesal Penal. In: Derecho y sociedad no 25, 2005, p. 157-162.

DELGADO MENÉNDEZ, María Antonieta. La reforma procesal penal en el Perú: rompiendo moldes, conquistando metas y enfrentando pendientes. In: Derecho PUCP, №65, 2010, p. 69-91.

DRUETTA, Delia Crovie. Producir saber y comunicarlo en la era digital. In: La era digital. primer congreso internacional de comunicación. México: Universidad Autónoma de Tamaulipas, (s/a), p. 63-84. Disponible en:

https://www.eumed.net/librosgratis/2009b/526/Producir\%20saber\%20y\%20comunicarlo\%20en\%20la\%20era\%20d igital.htm

GÁLVEZ VILLEGAS, Tomás Aladino, RABANAL PALACIOS, William y CASTRO TRIGOSO, Hamilton. El Código Procesal Penal. Comentarios descriptivos, 
explicativos y críticos. Lima: Jurista editores, 2008.

FACCHINI Neto, Eugenio. Reflexões histórico evolutivas sobre a constitucionalização do direito privado. In: SARLET, Ingo Wolfang (Org.) Constituição, Direitos Fundamentais e Direito Privado. Porto Alegre: Livraria do Advogado, 2010.

FACHIN, Luiz Edson. Direito civil: sentidos, transformações e fim. Rio de Janeiro: Renovar, 2015.

FREITAS, Cinthia O. de A. Redes sociais: Sociedade tecnológica e inclusão digital. In: Wachowicz, Marcos. (coord.) Direito da sociedade da informação \& propriedade intellectual, Curitiba: Juruá, 2012.

KIOMI MORI, Cristina. Políticas Públicas para a inclusão digital no Brasil: aspectos institucionais e efetividade em iniciativas federais de disseminação de telecentros no período 2000-2010. (teses apresentada na Universidade de Brasília), 2011. Disponible https://repositorio.unb.br/bitstream/10482/10560/1/2011 CristinaKiomiMori

MATTOS, Fernando Augusto Mansor y SANTOS, Bruna Daniela Dias Rochetti. Sociedade da informação e inclusão digital: uma analise crítica. In: Liinc em Revista, marz 2009, p. 117-132. Disponible en: http://revista.ibict.br/liinc/index.php/liinc/article/viewFile/247/198. Acceso en 20 de junio der 2013.

MATOS, Luis M. Barundi, JAKOBI, Karin B y RIBEIRO, Marcia C. Pereira. Acesso à informação e desenvolvimento socioeconômico. In: Wachowicz, Marcos. (coord.) Direito da sociedade da informação \& propriedade intelectual. Curitiba: Juruá, 2012, p. 119-135.

MERRYMAN, John Henry. La tradición jurídica romano- canónica. ํㅜㄹ. México D. F.: FCE, 2009.

MEZZAROBA, Orides; BERNIERI, Juliana y BIER, Clerilei. Os desafios da governança no novo século, as reformas estatais e a accountability. In: ROVER, Aires et. al. Direito, governança e tecnologia: princípios, políticas e normas do Brasil e da Espanha, Florianopolis: Conceito editorial, 2014.

NASER, Alejandra y CONCHA, Gastón. El gobierno electrónico en la gestión pública, Santiago de Chile: Comisión Económica para América Latina y el Caribe, 2011, p. 15-16. Disponible en: https://repositorio.cepal.org/bitstream/handle/11362/7330/1/S1100145 es.pdf Acceso en: 18/05/2015.

NEVES, Marcelo. Entre Hidra e Hércules: principios e regras constitucionais como diferença paradoxal do sistema jurídico. São Paulo: Editora WMF Martins Fontes, 2013.

RIBEIRO, Marcia C. P., BENEDETTI, Andréa R. de Morais y MACIEL, Oscar D. A 
era da informação e a modernização tecnológica do judiciário. In: Wachowicz, Marcos. (coord.) Direito da sociedade da informação \& propriedade intelectual. Curitiba: Juruá, 2012, p. 67-91.

ROSSI, Amélia do Carmo Sampaio. Neoconstitucionalismo: ultrapassagem ou releitura do positivismo jurídico?. Curitiba: Juruá, 2011.

SAN MARTÍN CASTRO, Cesar. Derecho Procesal Penal. Lima: Grijley, 2003.

SAN MARTÍN CASTRO, Cesar. La reforma del proceso penal peruano. Revista Peruana de Derecho Procesal II, Marzo 1998, p. 227- 257.

SALAS FERRO, Percy. El proceso judicial electrónico en el Perú. Revista de Investigación de la Academia de la Magistratura Vol. 1, №1, 2019, p. 15-43.

WACHOWICZ, Marcos y CASAGRANDE, Thais de Santos. A inclusão digital dos advogados: Gestao da tecnologia da informação e comunicação nos escritórios de advocacia. In: (coord.) Direito da sociedade da informação \& propriedade intelectual. Curitiba: Juruá, 2012, p. 93-117.

ZAGREBELSKY, Gustavo. El derecho dúctil. Ley, derechos, justicia, Madrid: Trota, 2011. 